\title{
A comparative study of the film cooling hole configuration effects on the leading edge of asymmetrical turbine blade
}

\author{
Mustapha BenABeD ${ }^{\mathrm{a}}$ \\ Laboratoire de Mécanique Appliquée, Faculté de Génie-Mécanique, Université des Sciences et de la Technologie d'Oran, \\ BP 1505 El-Mnouar, Oran, Algeria
}

Received 2 July 2010, Accepted 2 December 2010

\begin{abstract}
The focus of this comparative-numerical study is to investigate the effects of advanced cooling hole geometries on film cooling effectiveness. Computational results are presented for a row of coolant injection holes on each side of an asymmetrical turbine blade model near the leading edge. Six film cooling configurations are considered in the present study, namely: (1) a cylindrical film hole, (2) a shaped film hole, (3) a uniform film slot, (4) a convergent film slot, (5) a crescent film hole, and (6) a trenched film hole. All simulations are conducted for the same density ratio of 1.0 and the same inlet plenum pressure. A new parameter, $R c$, is defined to measure the rate of blade coverage by the film cooling. Results show that, at the suction side, except for the trenched case, all configurations provide an increase of film effectiveness, specially the crescent slot case which provides the highest increase over the baseline case. On pressure side, the five configurations produce better quality of cooling and an enhancement which reaches $60 \%$ for the crescent hole case. The best blade coverage by the film cooling is allotted to the two cases: uniform and converge slot configurations.
\end{abstract}

Key words: Film cooling effectiveness / coverage ratio / SST turbulence model / hole configuration

\section{Introduction}

Turbine inlet temperatures continue to increase to provide more efficient engines with less fuel consumptions and pollutions. This necessitates the design of more advanced cooling schemes for gas turbine blades, such as advanced film cooling configurations that provide better cooling to the blades while using minimum bled coolant air from the compressor. Advanced film cooling methods make use of different hole shapes such as the shaped hole, uniform slot, convergent slot, crescent hole, and trenched hole.

Several theoretical, experimental and numerical investigations have been conducted in order to understand the complex mechanisms in relation to the film cooling process. These studies are conducted either for flat plate [1-5] and/or leading edge turbine parts [6-10] and several geometrical parameters are investigated. The main objective of the above studies is to provide new concepts of geometrical disposition in order to maximize the film cooling effectiveness while retaining the minimum blowing ratio.

To the best of the author' knowledge, it seems that there is no study in the open literature on film cooling

${ }^{a}$ Corresponding author: bennabed@yahoo.fr from different hole cooling configurations on an asymmetrical turbine blade model cooling a-part from cylindrical or shaped holes [11-15]. There are only some studies on various hole configurations but for a flat plate [16-18] or for a symmetrical turbine blade model only $[8,16,17,19$ 21].

The aim of the present numerical work is to investigate the effects of the five hole configurations on the film cooling flow structure compared to that of classical cylindrical hole configuration for gas turbine blades.

\section{Geometry}

The blade used here is called the AGTB B1 and corresponds to a high pressure turbine cascade with showerhead injection. The blade is designed with two rows of ejection holes, one in the pressure side and the other one in the suction side. The two rows are in the vicinity of the leading edge corresponding on a showerhead film cooling configuration. The experimental studies, concerning cylindrical holes, were conducted by Ardey and Fottner $[12,13]$ who provides the aerodynamic data for several configurations including streamwise and lateral injections. This experimentation is considered as a test case 


\section{Nomenclature}

\begin{tabular}{|c|c|c|}
\hline$A$ & blade area & {$\left[\mathrm{m}^{2}\right]$} \\
\hline$B$ & blowing ratio & {$[-]$} \\
\hline$D$ & hole diameter & {$[\mathrm{m}]$} \\
\hline$H$ & vane height & {$[\mathrm{m}]$} \\
\hline$L$ & axial chord length & [m] \\
\hline$M$ & blowing ratio & {$[-]$} \\
\hline$M a$ & Mach number & {$[-]$} \\
\hline$R e$ & Reynolds number & {$[-]$} \\
\hline$T$ & temperature & {$[\mathrm{K}]$} \\
\hline$T u$ & turbulence intensity & {$[-]$} \\
\hline$W$ & blade width & {$[\mathrm{m}]$} \\
\hline$P$ & pressure & {$[\mathrm{Pa}]$} \\
\hline \multirow[t]{2}{*}{$C_{\mathrm{s}}$} & surface cooling quality & \\
\hline & $C_{\mathrm{s}}=\overline{\bar{\eta}} / S_{\mathrm{e}}$ & {$\left[\mathrm{mm}^{-2}\right]$} \\
\hline \multirow[t]{2}{*}{$R \mathrm{c}$} & film cooling coverage ratio & \\
\hline & $R c=\frac{S_{c}}{S_{t}} \times 100$ & {$[-]$} \\
\hline St & total surface area & {$\left[\mathrm{mm}^{2}\right]$} \\
\hline$S c$ & surface coveraged by the film cooling for $\eta \geq \eta_{\min }$ & {$\left[\mathrm{mm}^{2}\right]$} \\
\hline$S_{\mathrm{e}}$ & surface injection exit area & {$\left[\mathrm{mm}^{2}\right]$} \\
\hline$x, y, z$ & Cartesian coordinates & {$[\mathrm{m}]$} \\
\hline$s$ & coordinate along vane surface & {$[\mathrm{m}]$} \\
\hline$t$ & pitch & {$[\mathrm{m}]$} \\
\hline$\alpha, \beta$ & flow angle & {$\left[{ }^{\circ}\right]$} \\
\hline$\beta_{\mathrm{S}}$ & staggering angle & {$\left[{ }^{0}\right]$} \\
\hline \multirow[t]{2}{*}{$\eta$} & adiabatic film cooling effectiveness & {$[-]$} \\
\hline & $\eta=\left(T_{\infty}-T_{\mathrm{aw}}\right) /\left(T_{\infty}-T_{\mathrm{c}}\right)$ & {$[-]$} \\
\hline $\bar{\eta}$ & lateral averaged adiabatic film cooling effectiveness & \\
\hline & $\bar{\eta}=\frac{1}{W} \int_{0}^{W} \eta(z) \mathrm{d} z$ & {$[-]$} \\
\hline \multirow[t]{2}{*}{$\overline{\bar{\eta}}$} & area averaged film cooling effectiveness & \\
\hline & $\overline{\bar{\eta}}=\frac{1}{A} \iint \eta \mathrm{d} A$ & {$[-]$} \\
\hline \multirow[t]{2}{*}{$\Delta \overline{\overline{\eta_{\mathrm{E}}}}$} & percent enhancement in area-averaged effectiveness & \\
\hline & $\Delta \overline{\overline{\eta_{\mathrm{E}}}}=\left[\left(\overline{\bar{\eta}}-\overline{\bar{\eta}}_{\text {baseline }}\right) / \overline{\bar{\eta}}_{\text {baseline }}\right] \times 100$ & {$[-]$} \\
\hline \multicolumn{3}{|c|}{ Subscripts } \\
\hline aw & adiabatic wall & \\
\hline c & cooling air condition & \\
\hline PS & pressure side & \\
\hline SP & stagnation point & \\
\hline SS & suction side & \\
\hline
\end{tabular}

for numerical calculations for the shower head film cooling configuration. Therefore, this particular blade has been numerically investigated by several authors who have presented thermal computations that include both streamwise and lateral injections. The geometry baseline case details of the blade are illustrated in Figure 1. A total of six film holes geometries, which have been used, is presented in Figure 2. The new geometries used were selected among the configurations of holes already applied to the flat plate and/or the symmetrical blade.

The computational domain and the boundary conditions are represented in Figure 3. The symmetry boundaries are applied at the top and bottom planes bounding the domain. At the two periodic boundaries of the turbine cascade, translational periodicity, with automatic periodic mesh connection method [22], are applied. At walls, the no-slip condition is used, i.e., the velocity components of the flow are set to zero. The walls are considered as adiabatic boundaries with regard to the energy equation. The fixed static pressure $P_{2}$ at outlet boundary and the total pressure $P_{\mathrm{t}, 1}$ and the total temperature $T_{\mathrm{t}, 1}$ at the inlet boundary, are prescribed, such as to match the corresponding experimental conditions (Tab. 1). The experimental investigation requires taking for, the main flow simulation, a turbulence intensity of $5 \%$, and a dimensionless eddy viscosity of 100 . In order to simulate the calmer conditions prevailing in the plenum inlet boundary region, lower values are used for the turbulence intensity and the eddy viscosity ( $1 \%$ and 10 respectively).

A structured computational grid was developed using the ICEM grid generator. Three grids, of the I type, were generated, and referred to as coarse (close to that used by [15]), medium and fine, comprising 350000,471000 and 600000 hexahedral elements, respectively. Since the computations were performed by the SST model with automatic [22] wall functions, care was taken so that the maximum $y+$, at the wall-adjacent cells, was kept above the value of 1 . A preliminary grid dependence study shows 


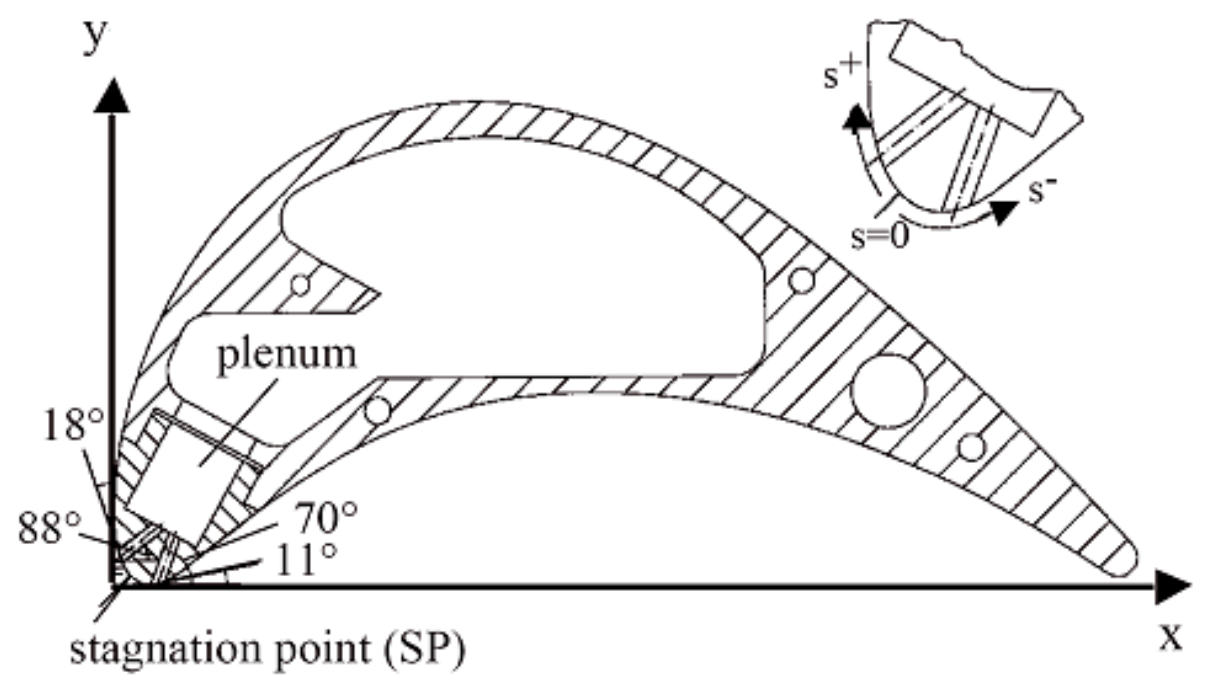

Fig. 1. AGTB blade geometry [14].

Table 1. Cascade geometry and parameters [14].

\begin{tabular}{ll}
\hline \multicolumn{2}{c}{ Geometry } \\
\hline Chord length: $L=250 \mathrm{~mm}$ & Pitch ratio: $t / L=0.714$ \\
Vane height: $H=300 \mathrm{~mm}$ & Staggering angle: $\beta_{\mathrm{S}}=73.0^{\circ}$ \\
\hline \multicolumn{2}{c}{ Aerodynamics } \\
\hline \multicolumn{2}{c}{ Cooling configuration (holes) } \\
Inlet $R e$ number: $R e_{1}=371000$ & Isentropic exit $M a$ number: $M a_{2 \text { is }}=0.95$ \\
Inlet flow angle: $\alpha_{1}=43^{\circ}$ & Exentropic exit $R e$ number: $R e_{2 \text { is }}=695000$ \\
\hline \multicolumn{2}{c}{ Cojection angle SS: $110^{\circ}$} \\
\hline Position $s / L$ SS: 0.02 & Ejection angle PS $120^{\circ}$ \\
Position $s / L$ PS: -0.03 & Hole length: $12.5 \mathrm{~mm}$ \\
Hole diameter $D: 3.00 \mathrm{~mm}$ &
\end{tabular}

Table 2. Experimental boundary conditions [14].

\begin{tabular}{lccc}
\hline Flow property & \multicolumn{3}{c}{ Blowing ratio $M=(\rho c)_{\mathrm{c}} /=(\rho c)_{1}$} \\
\hline Blowing ratio & $M=0.7$ & $M=1.1$ & $M=1.5$ \\
\hline Total pressure $p_{\mathrm{t}, 1}$ & $19620 \mathrm{~Pa}$ & $19650 \mathrm{~Pa}$ & $19620 \mathrm{~Pa}$ \\
\hline Total temperature $T_{\mathrm{t}, 1}$ & $303.15 \mathrm{~K}$ & $303.15 \mathrm{~K}$ & $303.15 \mathrm{~K}$ \\
\hline Main flow angle $\alpha_{1}$ & $43^{\circ}$ & $43^{\circ}$ & $43^{\circ}$ \\
\hline Static pressure $p_{2}$ & $14710 \mathrm{~Pa}$ & $14640 \mathrm{~Pa}$ & $14560 \mathrm{~Pa}$ \\
\hline \multicolumn{4}{c}{ Cooling fluid inlet conditions } \\
\hline Total pressure $p_{\mathrm{t}, \mathrm{c}}$ & $20060 \mathrm{~Pa}$ & $21710 \mathrm{~Pa}$ & $24130 \mathrm{~Pa}$ \\
\hline$\left(T_{\mathrm{t}, \mathrm{c}} / T_{\mathrm{t}, 1}\right)$ & 1 & 1 & 1 \\
\hline
\end{tabular}

that the medium structured multi bloc grid (Fig. 4), is the best compromise between precision and available computational facilities.

The basic case, which corresponds to Ardey's experimentation is used here for computational validation. Once the numerical results for the first cylindrical geometry were validated against the experimental results, it was then used as a benchmark for the other configurations.

The boundary conditions used for the basic case are matching those of Ardey and presented in Table 2, which corresponds to three different blowing ratios. Note that in Ardey's experimentation the temperature ratio is main- tained to 1 , while in the thermal studies $[15,23]$, the temperature ratio was changed to 0.5 which corresponds to the ratio of the air temperature at the final compressor stage and the turbine inlet temperature under design conditions.

\section{Numerical model}

The present simulations were conducted using the ANSYS-CFX code. In CFX a Finite Volume approach with parts of the finite element method is implemented. 


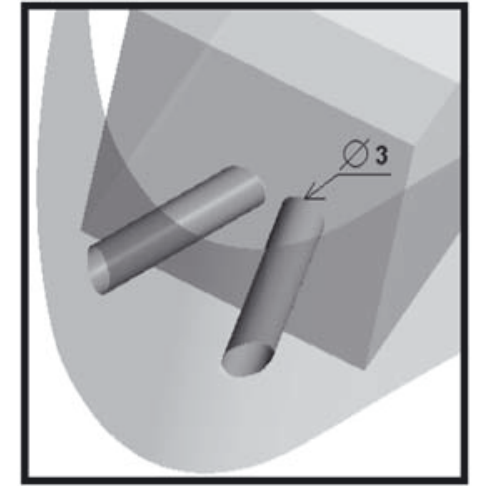

(a)

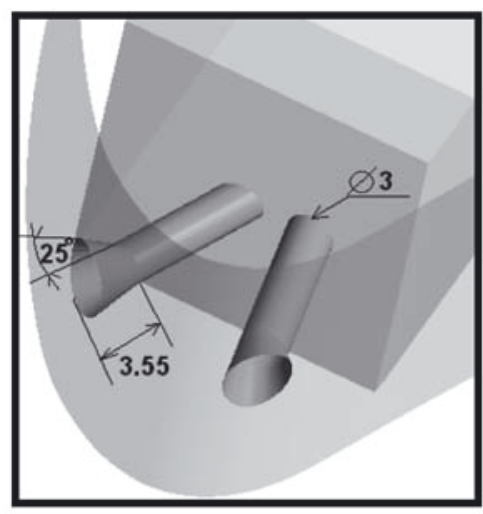

(b)

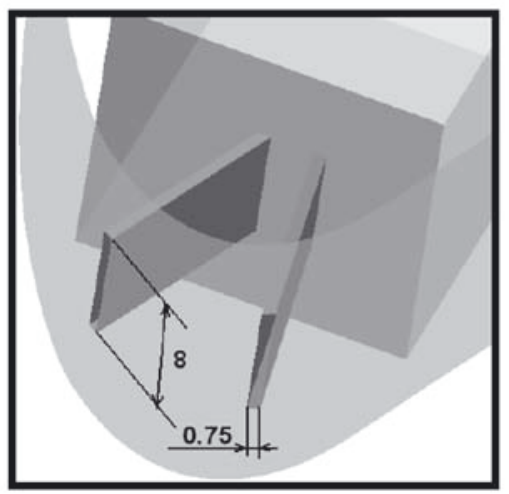

(c)

Fig. 2. Solid model for different film cooling configurations (d) Convergent slot. (e) Crescent hole. (f) Trenched hole.

By doing this a higher degree of geometric flexibility as typical for Finite-Element-approaches together with the strict mass conservation of Finite Volume-methods is achieved. The Navier-Stokes equations are discretised in an unstaggered, collocated way and solved by an algebraic multigrid solver. Instead of using a solution algorithm, CFX solves all conservation equations in one linear equation system, with all equations being fully coupled.

In the present study, the turbulence closure is achieved by use of the well known shear stress transport (SST) $k$-omega based model proposed by Menter [24]. This

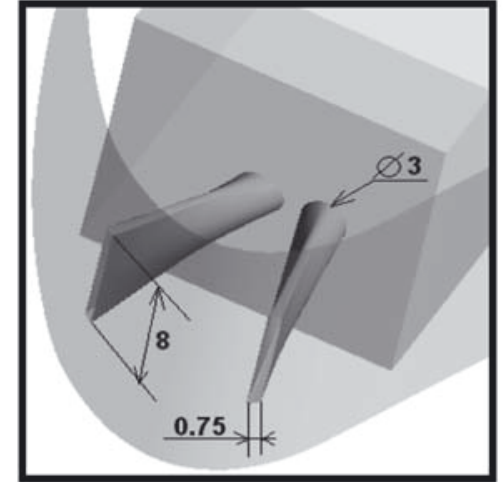

(d)

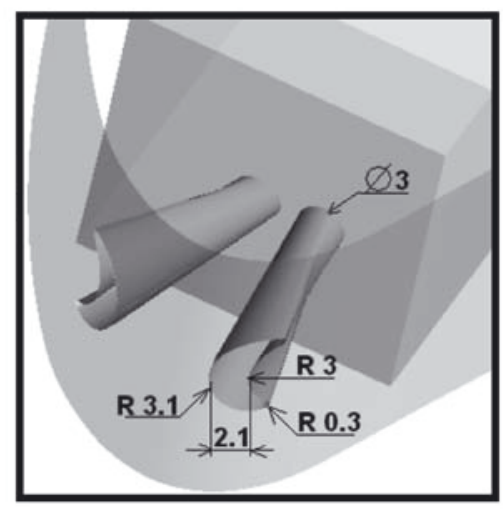

(e)

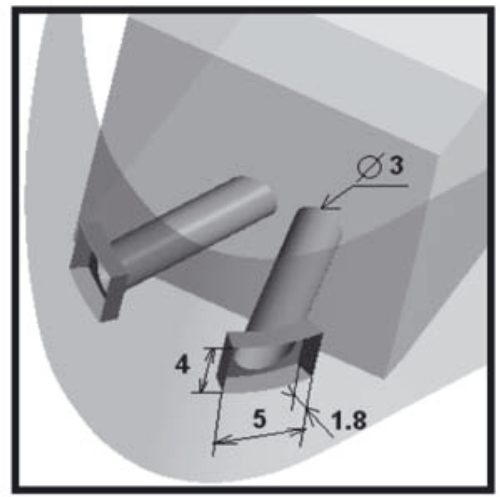

(f) (a) Cylindrical hole. (b) Shaped hole. (c) Uniform slot.

model is known to provide good compromise by combining the $k$-omega model of Wilcox near the wall regions and the high Reynolds $k$-eps model in the outer regions. The use of the two models is realized via a blending function, which switches from one to zero depending on the geometrical position of the integration point. Detailed explanation of the model formulation and test cases validations can be found on specific literatures of Menter's group. The turbulent heat flux is modeled by use of the eddy diffusivity hypothesis, where by analogy to eddy viscosity hypothesis the Reynolds fluxes of a scalar are linearly 


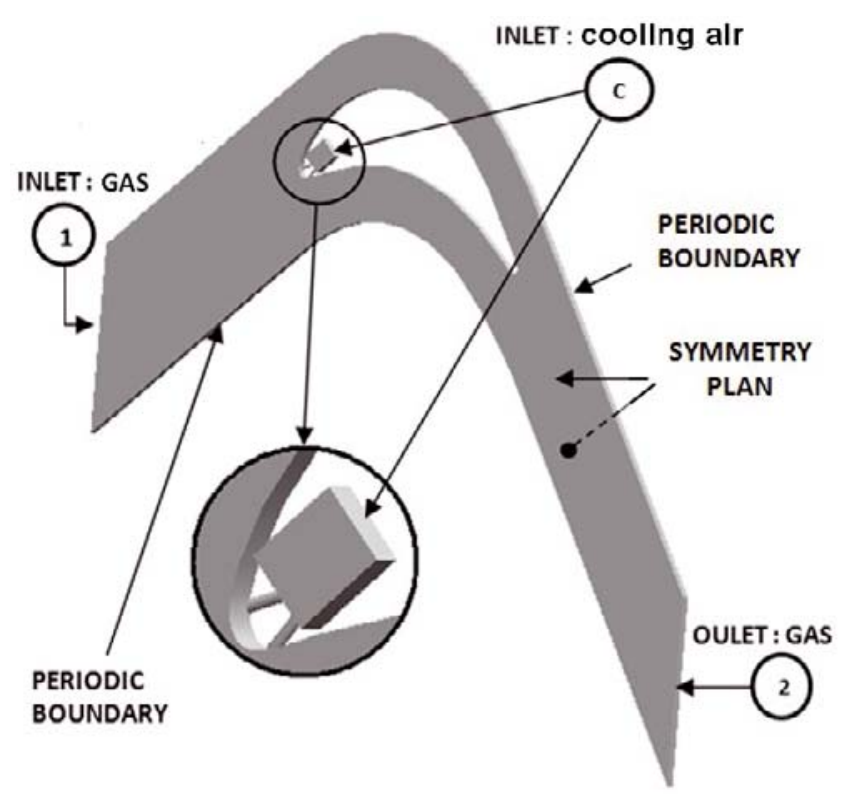

Fig. 3. Flow configuration and boundary conditions.

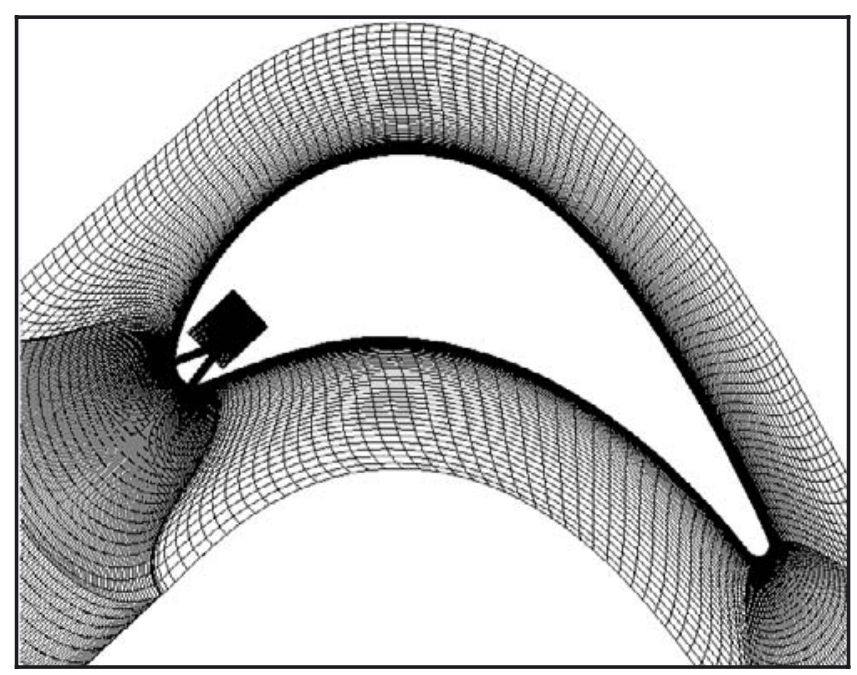

Fig. 4. Computational grid.

related to the mean scalar gradient. Eddy diffusivity is related to eddy viscosity by use of a turbulent Prandtl number, Menter [24].

\section{Results and discussion}

Preliminary computations are done with the same boundary conditions used by Ardey's experimentation. Static pressure distributions for the three blowing ratios along the symmetry plane are compared in Figures $5 \mathrm{a}-\mathrm{c}$ to the experimental measurements [14]. The comparison is satisfactory on the suction side and on the major part of the pressure side. Nevertheless, small differences can be depicted in the front part of the pressure side.

In second phase, the hole geometry effects are investigated for the other five hole configurations. Figures 6

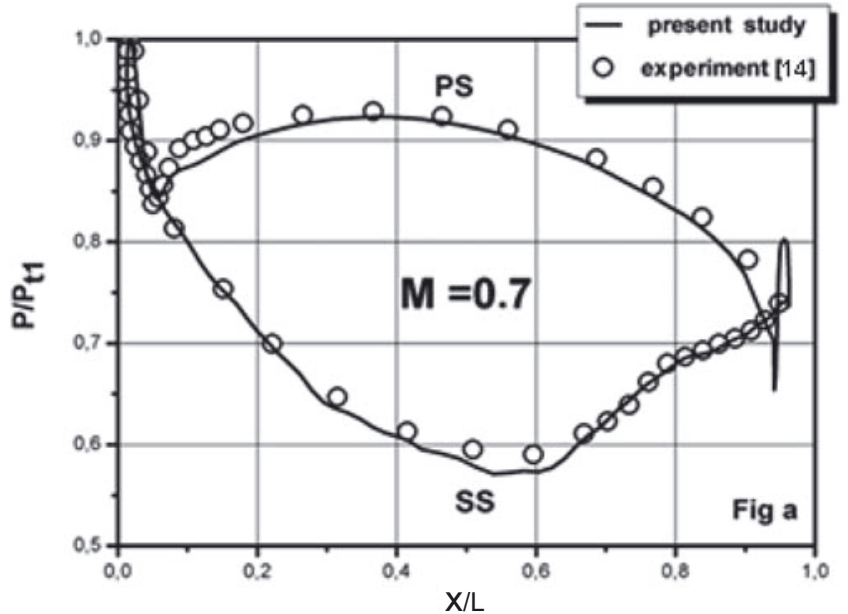

(a)

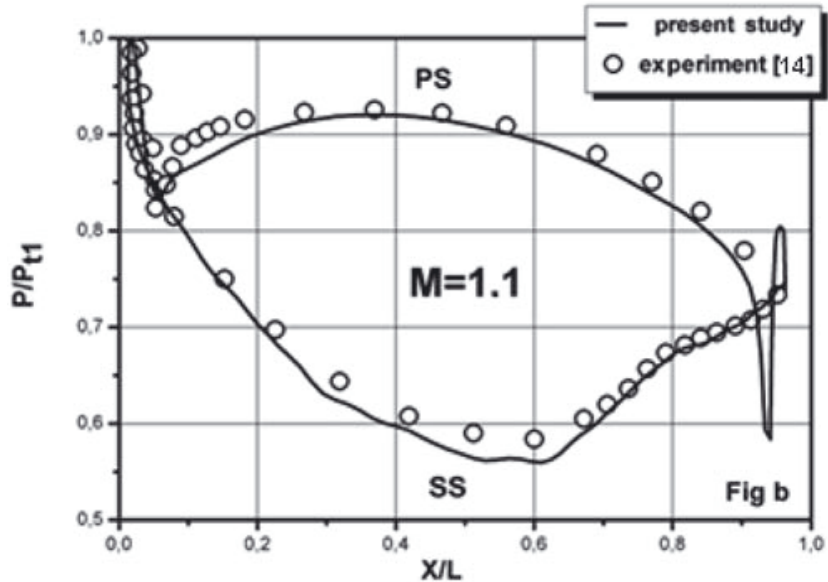

(b)

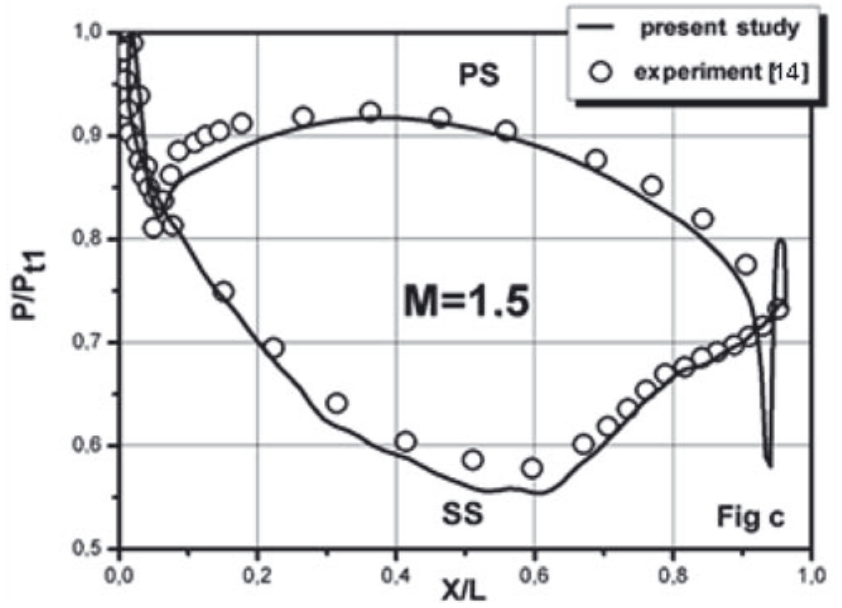

(c)

Fig. 5. (a-c) Static pressure distributions (midplane).

to 8 show at the midplane; the computed temperature, the velocity vector, and the effectiveness contours on the blade surface, respectively. It is clear, for all cases, from these figures that the hot gas is in direct contact with the blade surface in the stagnation point area between the two holes for the six configurations, and hence a higher thermal load on the blade material is to be expected. 


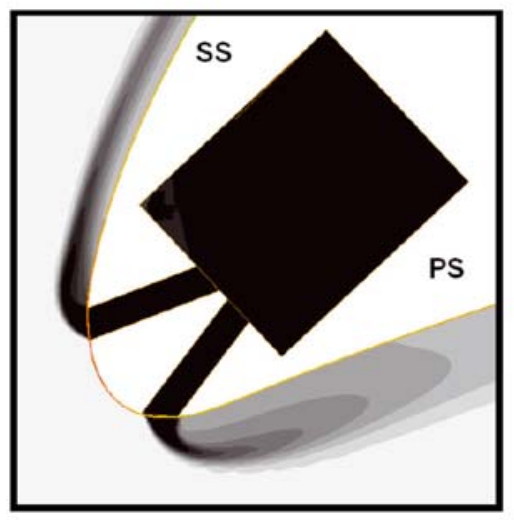

(a)

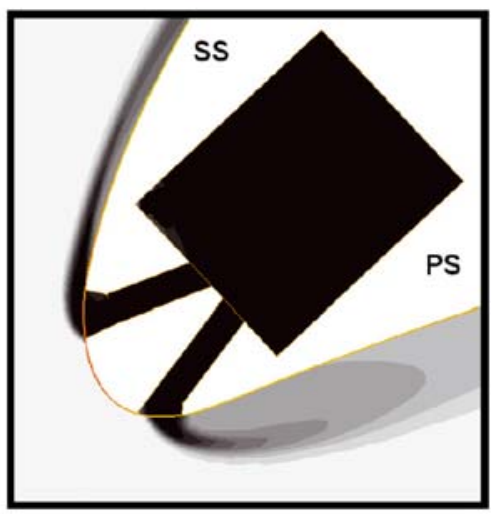

(c)

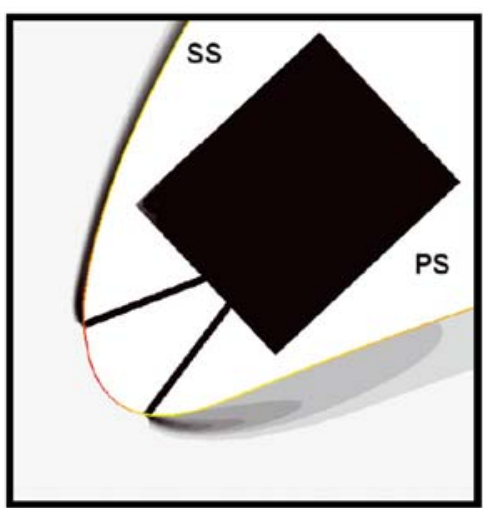

(e)

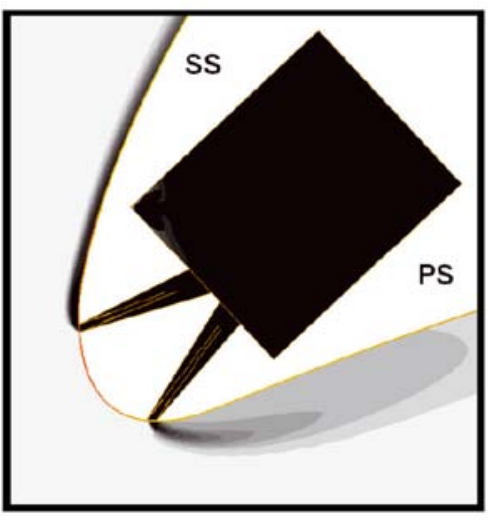

(b)

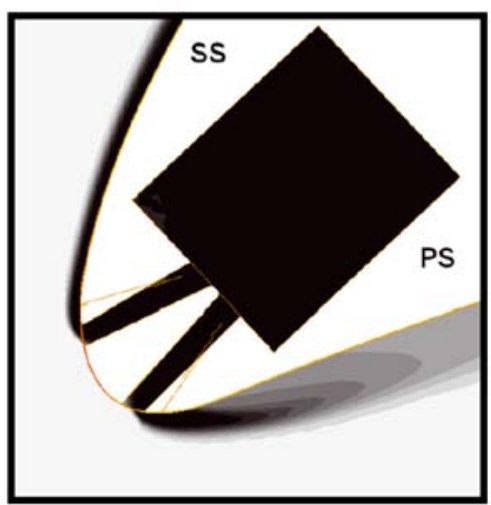

(d)

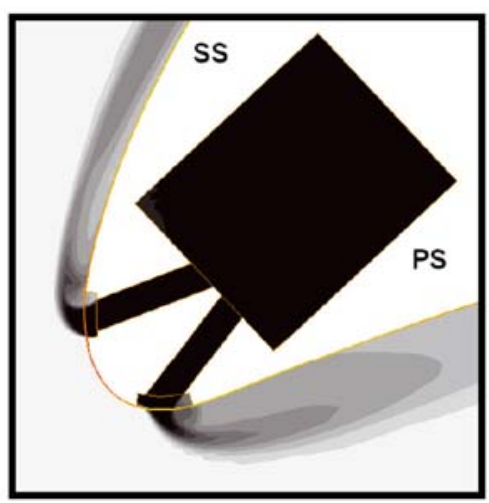

(f)

\section{Temperature}

303.150

286.308

269.467

252.625

235.783

218.942

202.100

185.258

168.417

151.575

[K]

Fig. 6. Computed temperature contours (midplane). (a) Cylindrical hole. (b) Convergent slot. (c) Shaped hole. (d) Crescent hole. (e) Uniform slot. (f) Trenched hole.

On the pressure side, it is seen, from Figure $6 \mathrm{a}$ that the baseline case shows the cooling jets are only in weak contact to the blade surface. The reason for this behaviour is to be found in the deep penetration of the jets and the consequent transportation of hot gas material. Because of the high momentum, shown in Figure 7a, the cooling air is away from the surface. This causes lower film effectiveness on the wall. For the others configurations where there is an increase area at the cooling exits, we must note that the expanded geometries decreased the coolant momentum so that coolant remained on the test surface. This is clearly visible when using shaped holes for example, Figure $6 \mathrm{c}$, which have a diffusing expansion at the exit of the hole. The diffusing exit of the coolant holes distributes the coolant over a broader area and reduces the coolant exit velocity, which reduces the tendency of the jet to separate from the surface. The result in term of film cooling effectiveness is very visible Figure $8 \mathrm{c}$. The phenomena are 


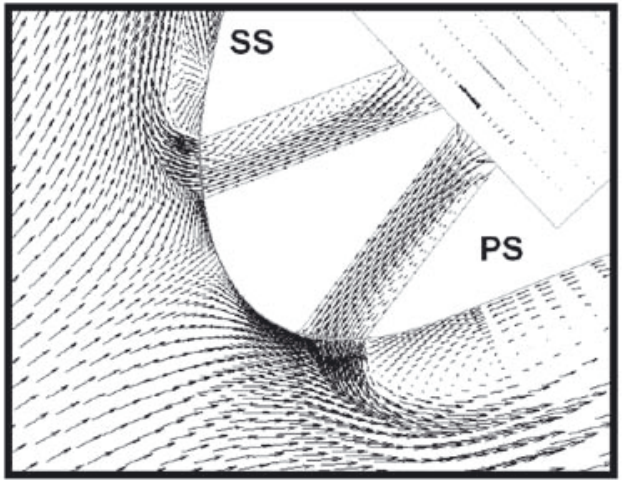

(a)

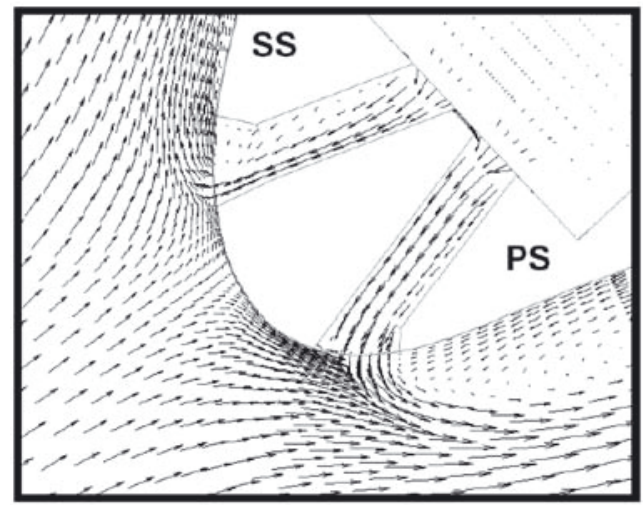

(c)

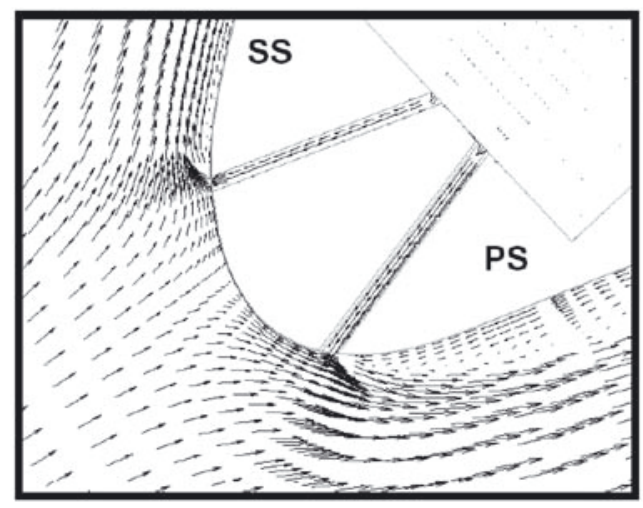

(e)

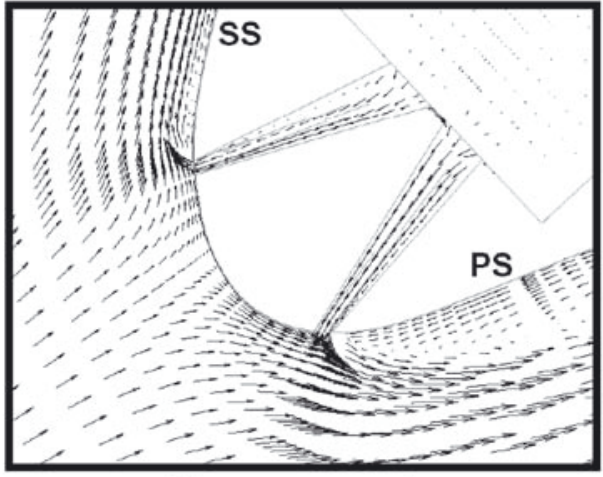

(b)

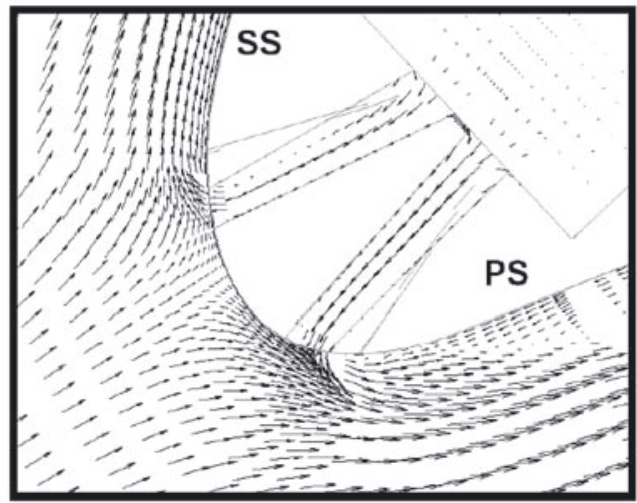

(d)

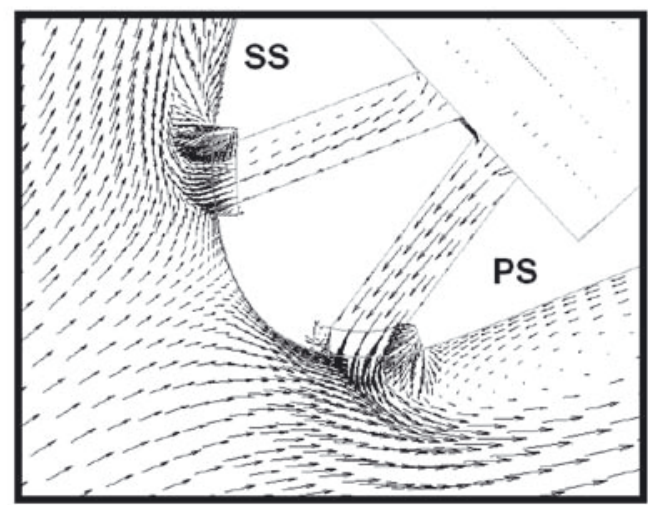

(f)

Fig. 7. Leading edge velocity vector plot distribution (midplane). (a) Cylindrical hole. (b) Convergent slot. (c) Shaped hole. (d) Crescent hole. (e) Uniform slot. (f) Trenched hole.

more accented for the convergent slot, the crescent slot, and the uniform slot, respectively in Figures $6 \mathrm{~b}, \mathrm{~d}$, and e. The recirculation zone is different in size and is the greatest for the baseline and the smaller for the uniform and convergent slot. It is interesting to note that for the uniform and convergent slots, and for the same shape hole exit, Figures $6 \mathrm{~b}$ and e, we have a smaller second stream for the uniform slot than that for the convergent slot. This will result in a different cooling effectiveness. The reason is that the flow rate in the injection hole configurations isn't the same, where the flow rate for the convergent slot case is greater because the circular shape at the plenum entry is more appropriate for admission of the coolant. For the trenched slot case Figure 6f, the downstream wall of slot causes a reverse flow and the cool air is trapped in the downstream corner and creates a small low-effectiveness region. The same remarks are applicable for the suction side but with a weaker reverse flow region.

For the baseline, on the suction side, the film cooling although the injection holes is brought closer to surface, however, it covers only one small surface. On the pressure side, the film cooling covers a rather broad zone, is very 


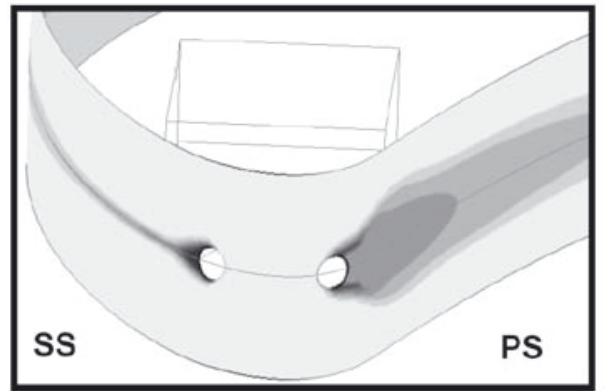

(a)

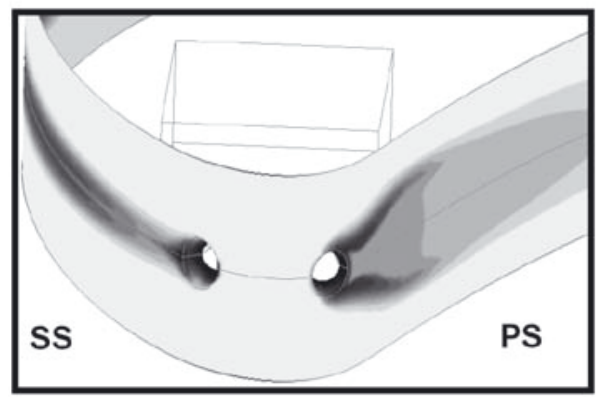

(c)

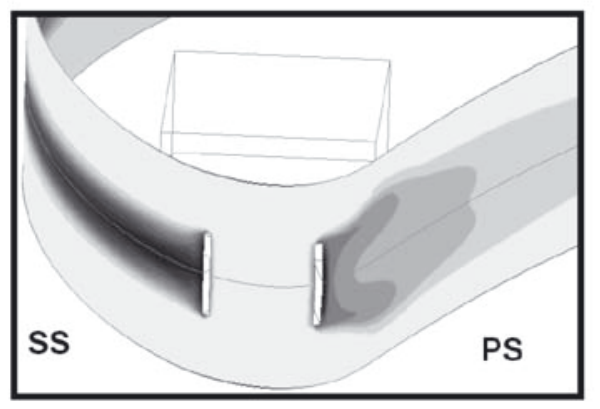

(e)

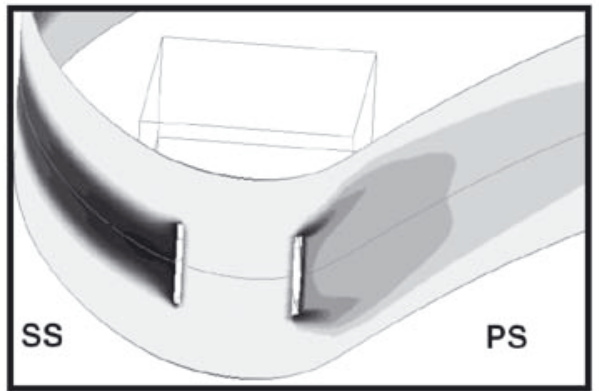

(b)

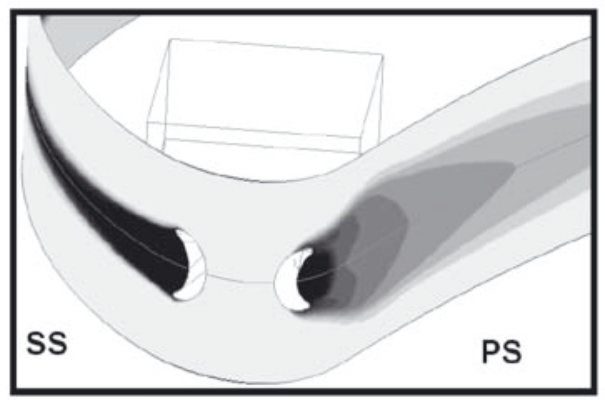

(d)

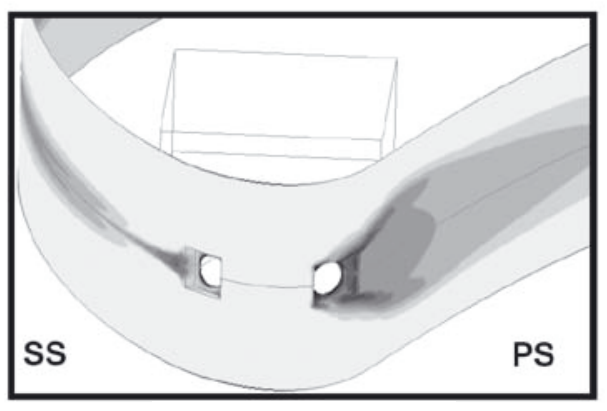

(f)

Fig. 8. Leading edge film cooling effectiveness contours. (a) Cylindrical hole. (b) Convergent slot. (c) Shaped hole. (d) Crescent hole. (e) Uniform slot. (f) Trenched hole.

close laterally to the surface which leads to an increase in film cooling effectiveness. However, the majority of film remains far away from surface because recirculation zone, which explains the reduction in film cooling effectiveness, Figure 8a. As it is already underlined, expansion of the hole exit decelerates the coolant jet resulting in a lower momentum flux and, consequently, less tendency for the coolant jet to separate. Furthermore, the lateral expansion presents a broader jet to the mainstream so that the mainstream has a greater impact on the jet and more effectively turns the jet toward the wall. The crescent shape, in addition reduces the possibility of hot gas ingestion on the upstream side of the hole because of the front curvature, decreases considerably the recirculation zone, at least in the midplane as shown in Figure $7 \mathrm{~d}$, thus has by consequence a better coverage of the blade by the film cooling and a better laterally spreading on surface that produces significantly higher effectiveness, especially at the suction side, as shown in Figure 8d. For converging and uniform slots, film effectiveness distribution is uniform in the spanwise direction and clearly well spread across the length of the slot. Considering that the flow rate for convergent slot is higher than that of uniform slot, the effectiveness film cooling is thus better, Figures $8 \mathrm{~b}$ and e.

Figure 9 presents the centerline film cooling effectiveness at the leading edge for the six cases. The exposure to the hot gas of the blade surface located between the injection holes for all the configurations, results in a quasi null film cooling effectiveness. The maximum film cooling effectiveness just at the exit of the film cooling is noted for the crescent slot. For the suction side, except the trenched slot, the other configurations produce a film cooling effectiveness higher than that of the baseline case. The superiority, in the decreasing order, of the crescent slot, the convergent slot, the uniform slot, and the shaped hole is obvious. Globally these four configurations produce an enhancement in effectiveness of minimum of 


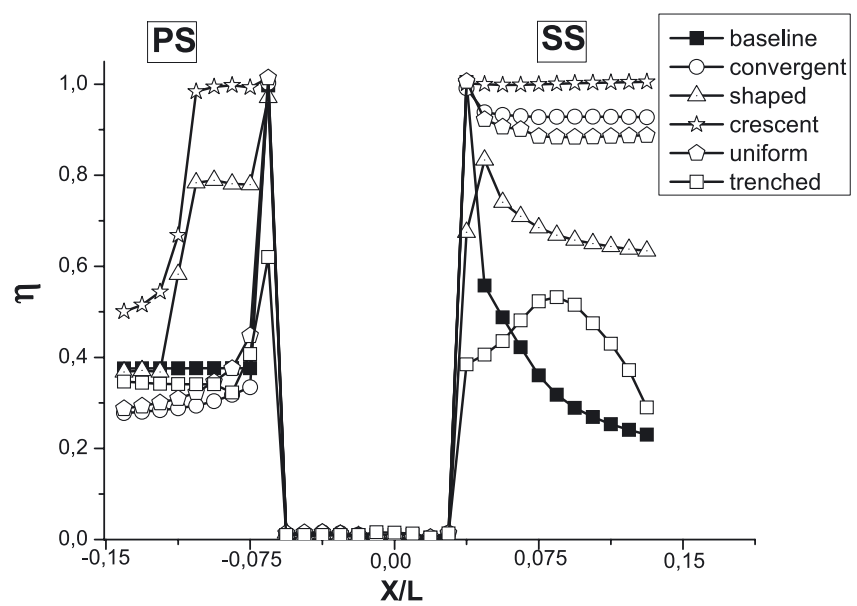

Fig. 9. Centerline film cooling effectiveness at the leading edge.

SS

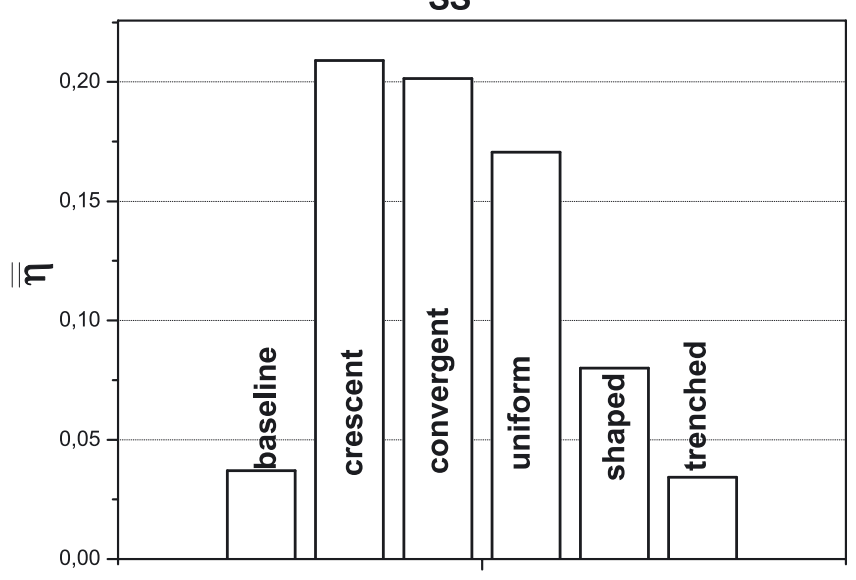

Fig. 10. Area averaged film cooling effectiveness on the suction side (leading edge).

$50 \%$. The trenched case, in the majority of the studied zone, presents a small enhancement compared to the case baseline. In the leading edge zone, it is important to notice that, for the following cases: crescent, convergent and uniform, the strong increase in the film cooling effectiveness, just after the exit, keeps a certain value, more or less constant. The case shaped undergoes a diminution of laterally averaged effectiveness then maintains a constant value. For the two remaining cases: trenched and baseline, they present a very marked monotonous reduction of the cooling effectiveness. In spite of its performances for a symmetrical blade [7], the trenched slot, investigated in present study for the asymmetrical blade, don't provide any advantage.

At the pressure side, in the leading edge, the two following holes configurations have exceeded, clearly, the baseline case, namely: crescent and shaped holes. For the other cases, the baseline case is obviously higher. Since the preceding figure relates to only the midplane zone, one needs another variable to concretely describe the behavior in the total zone studied.

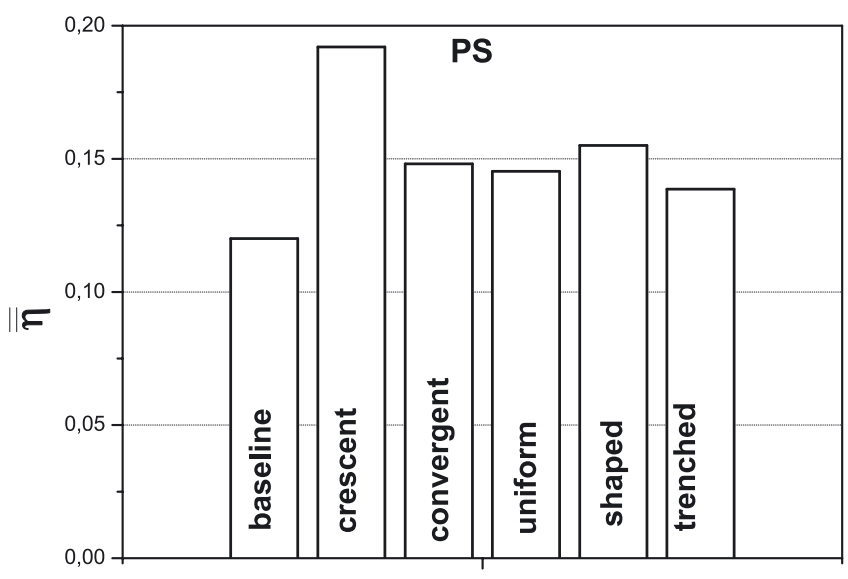

Fig. 11. Area averaged film cooling effectiveness on the pressure side (leading edge).

The influence of the injection located at the leading edge on the cooling of the leading edge zone is also studied through $\overline{\bar{\eta}}$ which represents the area-averaged effectiveness. On the suction side, Figure 10, except for the trenched case, all configurations, exceed the baseline case in term of $\overline{\bar{\eta}}$. The best result is allotted, without contest, to the crescent slot case (almost seven times the $\overline{\bar{\eta}}$ value for the baseline), followed meadows by the convergent and uniform slot cases. The low value of $\overline{\bar{\eta}}$ for the shaped hole case, compared to the three already quoted cases, is obvious. The percent enhancement in area-averaged effectiveness, for the shaped case, represents nevertheless $116 \%$ whereas there is a light reduction evaluated to $7.32 \%$ for the trenched case. The hole exit expansion, for this case, does not have any positive effect on the cooling effectiveness.

On pressure side, Figure 11, all the five configurations provide an increase of film effectiveness. We note that the enhancement realized at the pressure side is less than it is at the suction side. The best result is always recorded for the crescent case where the percent enhancement in area-averaged effectiveness, to the baseline case, reaches $60 \%$.

For the leading edge at the pressure side, the convergent and uniform slot cases present, no mistake as showed in Figure 11 , an increase in $\overline{\bar{\eta}}$ since they reach an enhancement of $23.4 \%$ and $21.1 \%$ respectively. For the trenched case, the percent enhancement in area-averaged effectiveness increase reaches a small, but nevertheless significant value of $15.5 \%$.

The comparison previously discussed was made without taking account of the difference between the injections sections of the various holes configurations (see Tab. 3). The effectiveness film cooling increase, for the same conditions of use, is allotted firstly, to the increase of the cooling exit surface. Generally, the larger is the exit cooling section the better is the film cooling effectiveness.

Secondly, for equal sections, the geometrical shape of the exit section can influence the cooling effectiveness. To emphasize that, the parameter $C_{\mathrm{S}}$ is introduced. This parameter expresses the intrinsic cooling quality of the area. 
Table 3. Area cooling exit.

\begin{tabular}{ccccc}
\hline \multirow{2}{*}{ Hole configuration } & \multicolumn{2}{c}{ PS } & \multicolumn{2}{c}{ SS } \\
\cline { 2 - 5 } & Area $\left[\mathrm{mm}^{2}\right]$ & BR $[-]$ & Area $\left[\mathrm{mm}^{2}\right]$ & BR $[-]$ \\
\hline Cylindrical & 8.40 & 0.49 & 7.41 & 0.37 \\
Shaped & 15.68 & 0.47 & 17.49 & 0.29 \\
Uniform & 6.71 & 0.37 & 6.26 & 0.27 \\
Convergent & 7.29 & 0.45 & 6.23 & 0.33 \\
Crescent & 14.48 & 0.37 & 14.31 & 0.25 \\
Trenched & 22.92 & 0.44 & 18.47 & 0.46 \\
\hline
\end{tabular}

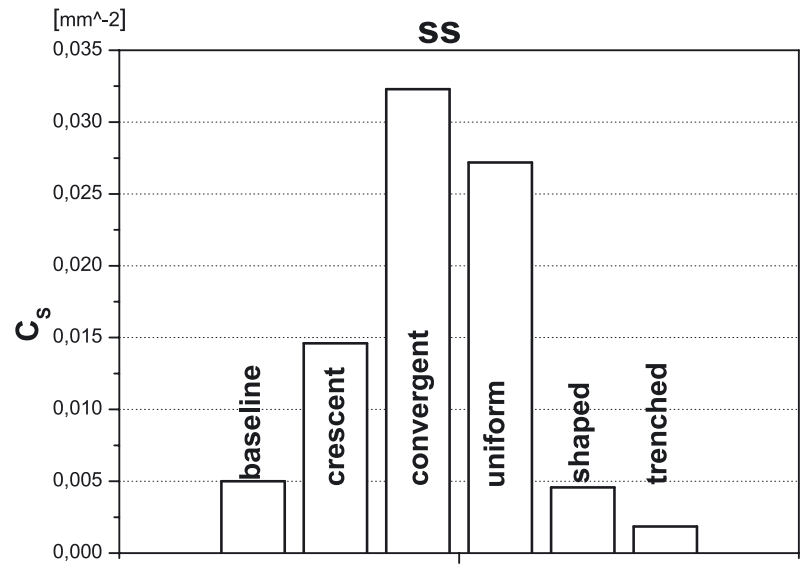

Fig. 12. Area averaged film cooling effectiveness per unit of coolant exit area at SS (leading edge).

Figures 12 and 13 show, without ambiguity, that the configurations of the convergent and uniform slots present the highest $C_{\mathrm{s}}$. It is, thus, the narrow rectangular shape which gets the best cooling effectiveness for a minimal area. The most beneficial quality of the cooling injection holes in effectiveness term of cooling is thus its expansion in spanwise direction. As waited, the difference in behavior between the SS and the PS is always present, $C_{\mathrm{s}}$ is higher at the SS than the PS. One can affirm that the cooling effectiveness gain allotted to crescent and shaped holes configurations, see Figures 10 and 11, is primarily caused by the increase of the cooling exit area and not to the cooling quality of their shape. The choice between these configurations must be made by taking account of the area-averaged effectiveness: $\overline{\bar{\eta}}$, the intrinsic cooling quality of the area: $C_{\mathrm{s}}$, and the resistance to the various stresses which the blade undergoes. An exit cooling area with a strong $C_{\mathrm{s}}$ is not automatically acceptable in term of resistance, as it can weaken the blade enormously.

An important phenomenon must be approached; it is the coverage of the blade surface by the film cooling. Admittedly the strong cooling effectiveness intensity is generally desired but the good distribution of this effectiveness on the major part of the surface is more still required. It is always preferable to choose a configuration giving large coverage in spite of the low effectiveness intensity, that one with a reduced coverage and strong effectiveness intensity. Because the goal of the film cooling is precisely to avoid to the blade material reaching a

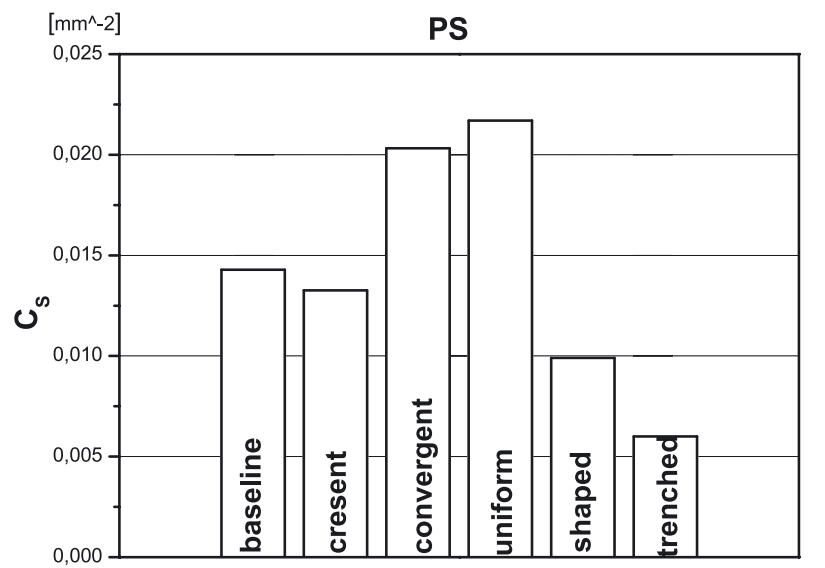

Fig. 13. Area averaged film cooling effectiveness per unit of coolant exit area at PS (leading edge).

certain critical temperature, therefore to ensure a minimum acceptable for the cooling effectiveness. To the best of the author' knowledge, no parameter in the open literature exists, to quantify this phenomenon. We can define the film cooling coverage ratio $(R c)$ as the percent of the surface covered by the film cooling, for a minimal film cooling effectiveness $\eta_{\min }$, on the entire zone considered surface. $\eta_{\min }$ represents the allowed minimum adiabatic effectiveness. An example is given, Figure 14, to illustrate this parameter. $\eta_{\min }$ differs enormously according to the cooling strategy adopted, considering the presence of several factors which interact at the same time: conduction, internal cooling, convection... For that and for the case which a minimal film cooling effectiveness is required, the range of 0.1 to 0.5 was adopted. At the SS (Fig. 15), globally, the convergent and uniform slots keep a coverage ratio between $22 \%$ and $27 \%$, the shaped hole between $7 \%$ and $16 \%$ and the crescent hole between $19.5 \%$ et $22.5 \%$. This last configuration seems insensitive with the $\eta_{\min }$ variations. The baseline and trenched slots configurations present the worst coverage ratio [ $4.4 \%$ to $0.46 \%]$. At PS (Fig. 16), the crescent case insensitivity is always present [22.7\% to $29.3 \%$ ]. In spite of their superiority on the other configurations, the cases uniform and convergent slot configuration present a sudden diminution of the coverage ratio from $\eta_{\min }$ equal to 0.3 . No change for the cases baseline and trenched slot, they always present the worst coverage ratio, but this last is definitely higher than that at the SS. 


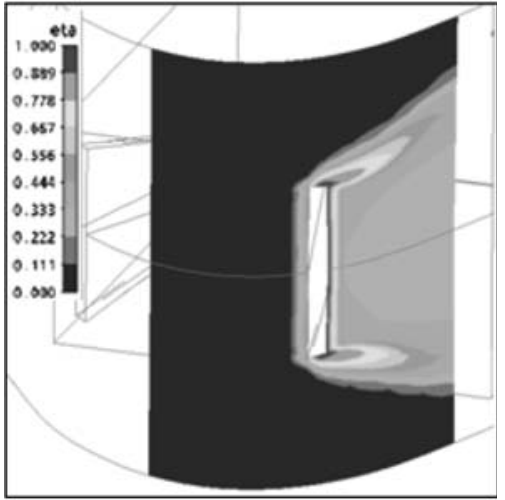

(a)

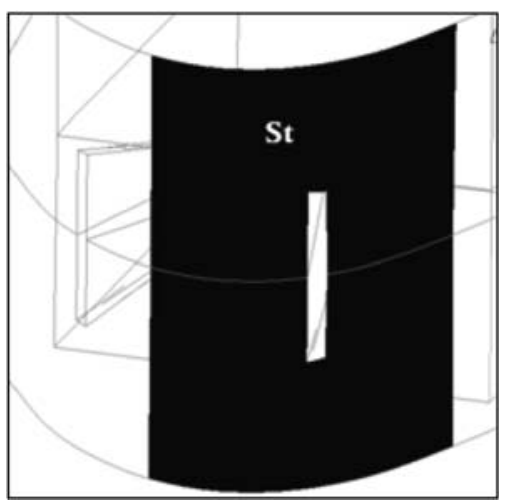

(b)

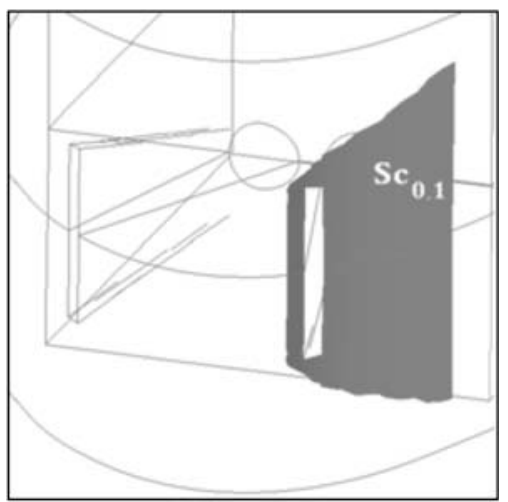

(c)

Fig. 14. Film cooling coverage ratio example illustration. (a) Distribution of $\eta$. (b) Total surface area $S_{\mathrm{t}}$. (c) Surface covered by the film cooling for $\eta \geq 0.1$.

Given the significantly improved performance of the five hole configurations, it is important to recognize the cost of manufacturing when comparing cylindrical and other configurations. Because of the complexity of producing of such hole geometry, manufacturing turbine blade with these configurations is considerably more expensive than cylindrical holes. In many cases, this additional cost is not warranted, and cylindrical holes are used [25]. Eight key factors are used to judge the potential performance for each film hole geometry including

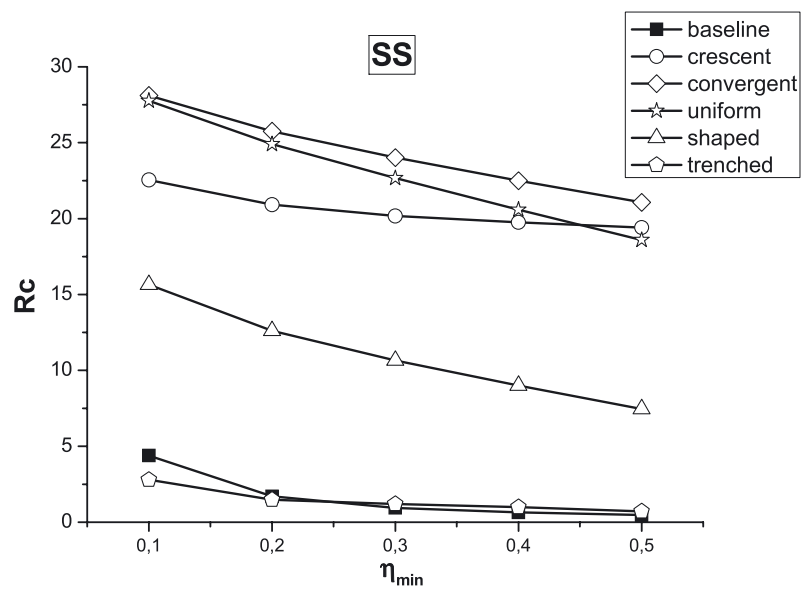

Fig. 15. Film cooling coverage ratio at suction side.

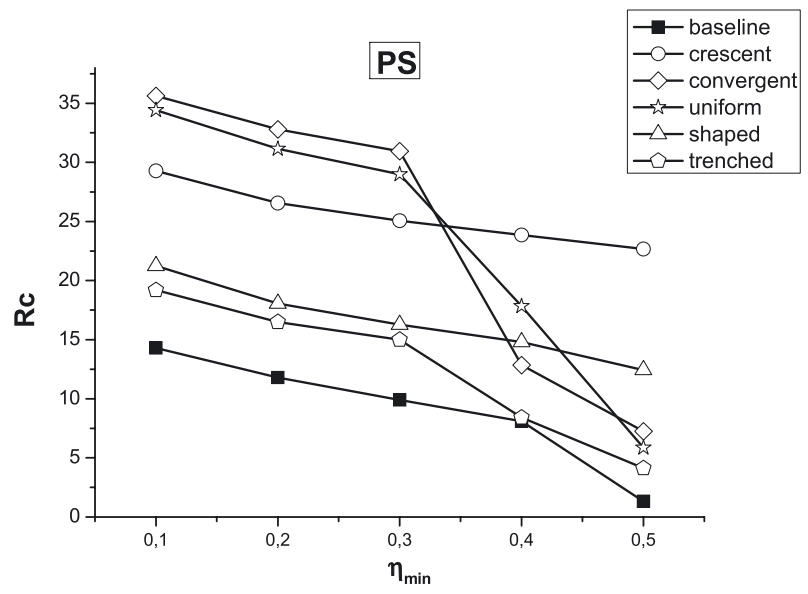

Fig. 16. Film cooling coverage ratio at pressure side.

adiabatic effectiveness, manufacturing, cost, repair, geometry sensitivity, flow sensitivity, operational tolerance, and strength/durability [26].

\section{Conclusions}

A detailed study on the effect of film cooling hole configurations has been conducted. This includes the presentation of computational results for a row of simple angle holes on each side of a asymmetrical turbine blade model near the leading edge. Six film cooling configurations, (1) a cylindrical film hole, (2) a shaped film hole, (3) a uniform film slot, (4) a convergent film slot, (5) a crescent film hole, and (6) a trenched film hole, are used. On pressure side, the five configurations produce better quality of cooling and an enhancement which reaches $60 \%$ for the crescent hole case. The coolant, in effect, stays closer to the surface and does not allow main entrainment and also spreads laterally. The film effectiveness distributions show stronger coverage especially for the four cases: crescent, shaped, convergent and uniform slot.

Globally and compared to the cylindrical holes, these four configurations provide an increase of film 
effectiveness. The enhancement realized at PS is less than it is at SS.

Even with the same geometries, the injection holes at SS and PS produce different behavior regarding the film cooling effectiveness. This is due mainly to asymmetrical form of the blade and consequently to the pressure field accompanied each side of the blade. A deeper analysis of the aero thermal field is needed in order to explain the associated phenomenon and propose an optimized film cooling configuration for the present blade model.

With the exception of the crescent slot case, unfortunately no hole configuration is completely beneficial for both sides of the blade with the same impact. A choice then will have to be essential according to the present conditions and the targeted goal. In conclusion, with this study we can say that, a blade with a crescent hole configuration will, surely, generate a cooling effectiveness notable increase, but the use of the convergent or uniform configuration is better, considering than more large surface is protected by the film cooling even with a lower cooling effectiveness.

\section{References}

[1] K.D. Walters, J.H. Leylek, A detailed analysis of filmcooling physics, part 1: streamwise injection with cylindrical holes, 1994, ASME Paper, 97-GT-269

[2] A. Azzi, B.A. Jubran, Numerical Modeling of Film Cooling from Short Length Stream-Wise Injection Holes, Heat and Mass Transf. 39 (2003) 345-353

[3] A. Azzi, B.A. Jubran, Numerical Modelling of Film Cooling from Converging Slot-Hole, J. Heat Mass Transfer 43 (2007) 381-388

[4] S. Baheri, S.P. Alavi Tabrizi, B.A. Jubran, Film Cooling Effectiveness from Trenched Shaped and Compound Holes, J. Heat Mass Transf. 44 (2008) 989-998

[5] S. Baheri, B.A. Jubran, S.P. Alavi Tabrizi, The Effect of Turbulence Intensity on Film Cooling of Gas Turbine Blade from Trenched Shaped Holes, ASME Paper \# GT2008-50318, Proc. ASME Turbo Expos 2008 Conference, June 9-13

[6] F. Nemdili, A. Azzi, G. Theodoridis, B.A. Jubran, Reynolds Stress Transport Modeling of Film Cooling at the Leading Edge of a Symmetrical Turbine Blade Model, J. Heat Trans. Eng. 29 (2008) 950-960

[7] S. Baheri, B.A. Jubran, S.P. Alavi Tabrizi, Computational Investigation of Film Cooling from Trenched Holes Near the Leading Edge of a Turbine Blade, J. Numerical Heat Transfer, Part A: Applications 53 (2008) 208-322

[8] F. Nemdili, A. Azzi, B.A. Jubran, Shower Head Film Cooling Effectiveness of a Symmetrical Turbine Blade Model - Effect of Lateral Injection, Proc. HT2007 2007, Paper \# HT2007-32081, ASME-JSME Thermal Engineering Summer Heat Transfer Conference, July 812

[9] M. Salcudean, I. Gartshore, K. Zhang, I. McLean, An experimental study of film cooling effectiveness near the leading edge of a turbine blade, Trans. ASME J. Turbomachinery 116 (1994) 71-79
[10] A. Azzi, B.A. Jubran, Influence of leading-edge lateral injection angles on the film cooling effectiveness of a gas turbine blade, Heat and Mass Transf. 40 (2004) 501-508

[11] G. Wagner, Experimental investigations of showerhead film cooling on the leading edge of a turbine blade, Ph.D. Thesis No: 3755, 2007, Laboratoire de thermique appliquée et de turbomachines, École Polytechnique Fédérale de Lausanne

[12] S. Ardey, L. Fottner, Flow Field Measurements on a Large Scale Turbine Cascade with Leading Edge Film Cooling by Two Rows of Holes, 1997, ASME Paper No. 97-GT524

[13] S. Ardey, L. Fottner, A Systematic Experimental Study on the Aerodynamics of Leading Edge Film Cooling on a Large Scale High Pressure Turbine Cascade, 1997, ASME Paper No. 98-GT-434

[14] S. Ardey, 3D-Messung des Strömungsfeldes um die filmgekühlte Vorderkante einer Referenzschaufel Ph.D. Thesis, University of the Armed Forces Munich, 1998

[15] D. Bohn, K. Kusterer, Aerothermal Investigation of Mixing Flow Phenomena in Case of Radially Inclined Ejection Holes at the Leading Edge, ASME J. Turbo Mach. 122 (2000) 334-339

[16] R.S .Bunker, A review of shaped hole turbine film-cooling technology, ASME J. Heat Trans. 127 (2005) 441-453

[17] Y. Lu, A. Dhungel, S.V. Ekkad, R.S. Bunker, Film Cooling Measurements for Cratered Cylindrical Inclined Holes, ASME Paper, GT2007-27386

[18] J.E. Sargison, S.M. Guo, M.L. Oldfield, G.D. Lock, A.J. Rawlinson, A converging slot-hole film-cooling geometrypart 1: low-speed flat-plate heat transfer and loss, ASME J. Turbomach. 124 (2002) 453-460

[19] Y. Lu, A. Dhungel, S.V. Ekkad, R.S. Bunker, Effect of Trench Width and Depth on Film Cooling from Cylindrical Holes Embedded in Trenches ASME Paper, GT2007-27388

[20] Y. Lu, Effect of hole configurations on film cooling from cylindrical inclined holes for the application to gas turbine blades, Int. J. Heat Fluid Flow 28 (2007) 922-931

[21] J.E. Sargison, S.M. Guo, M.L. Oldfield, G.D. Lock, A.J. Rawlinson, A converging slot-hole film-cooling geometrypart 2: transonic nozzle guide vane heat transfer and loss, ASME J. Turbomach. 124 (2002) 461-471

[22] ANSYS CFX 10.0 (2005) Documentations

[23] D. Lakehal, G. Theodoridis, W. Rodi, Three dimensional flow and heat transfer calculations of film cooling at the leading edge of asymmetrical turbine blade model, Int. J. Heat Fluid Flow 22 (2001) 113-122

[24] F.R. Menter, Zonal two-equation $k-\omega$ turbulence model for aerodynamic flows (1993) AIAA Paper, 93-2906

[25] D.G. Bogard, K.A. Thole, Gas Turbine Film Cooling, J. Propuls. Power 22 (2006) 249-270

[26] R.S. Bunker, Film Cooling: Breaking the Limits of Diffusion Shaped Holes Turbine 09 Symposium on Heat Transfer in Gas Turbine Systems, 2009, Antalya, Turkey

[27] Z. Gao, D.P. Narzary, J. Han, Film cooling on a gas turbine blade pressure side or suction side with compound angle shaped holes. Paper \# HT-2007-32098. In. Proc. of the ASME-JSME thermal engineering summer heat transfer conference, July 8-12, 2007, Vancouver, BC, Canada 